\title{
Study of endovascular treatment in obstructive aortoiliac lesions: Immediate and short-term results
}

Dinesh Joshi, Tarun Madan, Riyaz Charaniya, Pratik Raval*, Krutika Patel, Ajinkya Borhade, Rujuta Parikh, Anand Dhakne

U.N.Mehta Institute of Cardiology and Research Centre (UNMICRC), Civil Hospital Campus, Asarwa, Ahmedabad, Gujarat, India

\begin{abstract}
:
Objective: Aorto-iliac occlusive disease (AIOD) is a common atherosclerotic disease causing significant morbidity. Transatlantic intersociety consensus for the management of peripheral arterial disease (TASC II) recommends endovascular therapy (ET) for better management of patients with lesions type A and B. With the advent of endovascular therapy, type $C$ and $D$ lesions management is becoming more feasible with endovascular therapy than open surgery for aorto-iliac occlusive disease. We aimed to evaluate patients with AIOD and to describe short-term outcome of endovascular treatment for such lesions.

Methods: Patients with aorto-iliac occlusive diseases who underwent endovascular therapy were enrolled in the study. Their demographic data and risk factors were recorded. Patients were followed at 3 and 6 months and their primary patency rate and symptom status were recorded.

Results: We enrolled 100 patients with a mean age of 59.77 (8.75) years with the majority of patients being male. The most common presentation was claudication (59\%) followed by rest pain (31\%) and gangrene (20\%). The majority of patients had Transatlantic inter-society consensus (TASC) II type A (44\%) and type B (31\%) lesions; $15 \%$ of patients had types $\mathrm{C}$ lesions and the remaining $10 \%$ patients had type $\mathrm{D}$ lesions. Access site hematoma and contrastinduced nephropathy were present in $7 \%$ and $5 \%$ of patients respectively. Stent patency rate was $97 \%$ and $95 \%$ at 3 and 6 months follow up respectively.

Conclusion: Endovascular therapy in aorto-iliac occlusive disease is a safe, effective, and low-cost treatment option with a high patency rate and symptomatic improvement in the short-term.
\end{abstract}

Key words: Aorto-iliac occlusive disease, peripheral artery disease, endovascular treatment

(Heart Vessels Transp 2022; 6; doi: Doi: 10.24969/hvt.2021.298)

\section{Introduction}

Aorto-iliac occlusive disease (AIOD) commonly causes multiple chronic symptoms such as impotence, critical limb ischemia, claudication, and pelvic ischemia. Therefore, adequate revascularization strategy may improve quality of life. Aorto-iliac occlusive disease constitute around one-third of all peripheral artery diseases (1). Endovascular techniques and newergeneration stents now afford similar long-term patency rate compared to surgical bypass grafts. Endovascular stent placement has therefore become the most frequent revascularization strategy in patients with symptomatic iliac artery stenosis (2-4). Rutherford and Fontaine scoring systems for peripheral artery disease (PAD) are commonly used and they essentially divide patients with AIOD into those with no symptoms, intermittent claudication (IC), or critical limb ischemia (CLI).

Address for Correspondence: Pratik Raval, Department of Cardiology, UNMICRC, Civil Hospital Campus, Asarwa, Ahmedabad-380016, Gujarat, India E-mail: drpratikrava1144@gmail.com Mobile: 91-9099096743 Fax: 91-07922682092

Received: 28.10.2021 Revised: 17.12.2021 Accepted: 17.12.2021

CopyrightC 2022 Heart, Vessels and Transplantation

Doi: $10.24969 /$ hvt.2021.298

Heart, Vessels and Transplantation 2022; 6: doi: 10.24969/hvt.2020.298

Endovascular treatment of aorto-iliac lesions

Joshi et al.

Asymptomatic patients with peripheral artery disease would be unlikely to benefit from endovascular or surgical treatment and may experience treatmentrelated complications, therefore, intervention should 
be limited to those with lifestyle limiting claudication or limb-threatening ischemia. Non-invasive methods like duplex ultrasound and computed tomography (CT) angiography permit accurate, risk-free evaluation of peripheral artery disease (5).

The Transatlantic inter-society consensus (TASC II) for the management of peripheral arterial disease classifies infrarenal aorto-iliac occlusion, unilateral occlusion of both common iliac and external iliac, bilateral external iliac occlusion and unilateral common iliac, external iliac and common femoral diffuse stenosis as type D lesions. For such lesions, the traditional recommendation is open surgical procedure (bypass graft) (6) with a patency rate of $87.5 \%$ and $81.8 \%$ at 5 and 10 years, but with mortality and morbidity rate of $3.3 \%$ and $8.3 \%$ respectively (7). However, use of endovascular treatment for such lesions is not uncommon as many patients who need the intervention do not meet the criteria for surgery (8).

The aim of present study was to evaluate aorto-iliac occlusive disease using different diagnosis modalities like duplex ultrasound, CT angiography and invasive peripheral angiography and to describe short-term outcome of endovascular treatment for such lesions.

\section{Methods}

In the present prospective observational study, we recruited patients who had AIOD from December 2016 to January 2019. After obtaining ethical clearance and informed consent, patients with AIOD with TASC II class A to D were included in the study. Patients having recent myocardial infarction, active infection and pregnancy were excluded from the study. Written informed consent was taken from patient or their relative.

All patients were evaluated clinically and appropriate imaging study was done. After evaluation, patients underwent various endovascular treatments (balloon angioplasty, catheter directed thrombolysis, angioplasty with stent placement) as per discretion of treating physician. Right and left femoral and right brachial access was used to define anatomy and deploy stents. The stents (Absolute Pro and Omnilink Elite, Abbott Vascular) were used as per operator's discretion.

The contrast-induced nephropathy was defined as an absolute $(\geq 0.5 \mathrm{mg} / \mathrm{dl})$ or relative increase $(\geq 25 \%)$ in serum creatinine at $48-72 \mathrm{~h}$ after exposure to a contrast agent compared to baseline serum creatinine values, when alternative explanations for renal impairment have been excluded.

All the patients were followed at 3 and 6 months either telephonically or at outpatient clinic. Their demographic details, symptom status and patency rates were documented. Duplex ultrasound and if necessary, CT angiography were performed to assess stent patency.

Statistical Analysis: All statistical studies were carried out using SPSS v20 (IBM ${ }^{\circledR}$ SPSS Statistics ${ }^{\circledR}$ ). Continuous variables were expressed as the mean (standard deviation) and Categorical variables were expressed as percentage (\%). A nominal significance was taken as a two tailed $p$ value $<0.05$.

\section{Results}

We conducted a prospective observational study to describe the short-term outcomes of endovascular therapy for AIOD. Baseline characteristics of the total populations are shown in Table 1. Mean age of patients was 59.7 (8.75) years. Majority of patients were male $(91 \%)$ in our study. Intermittent claudication (59\%) was the most frequent presenting complaint. Almost one third patients had rest pain (31\%), $20 \%$ of patients had gangrene or ulcer. Erectile dysfunction was present in $16 \%$ cases. Most common co-morbidities were diabetes mellitus and dyslipidemia (37\% and 33\% respectively) followed by coronary artery disease (27\%), hypertension (26\%) and chronic kidney disease (CKD) (9\%). Majority of patients (86\%) were current smokers.

Majority of the patients belonged to class A (44\%) and class $\mathrm{B}(31 \%)$ of TASCI II classification; $25 \%$ of patients belonged to class C (15\%) and class D (10\%). Overall, 95\% patients underwent peripheral angioplasty with stent placement. Very few patients were treated with catheter directed thrombolysis (2\%) and $3 \%$ underwent both the procedures.

Hematoma and contrast-induced nephropathy were present in $7 \%$ and $5 \%$ patients respectively (Fig. 1). All the patients with contrast-induced nephropathy had pre-existing chronic kidney disease. No other major complications occurred during peri-procedural period. All the patients were followed for 6 months. Short-term stent patency rate was excellent $(98.9 \%$ at 3 months and $96.9 \%$ at 6 months) as mentioned in Table 2. 


\begin{tabular}{|l|c|}
\hline Table 1. Baseline clinical characteristics & $\mathbf{N}=\mathbf{1 0 0 ( \% )}$ \\
\hline Variables & $59.7(8.75)$ \\
\hline Age, years & $91(91)$ \\
\hline Gender, $\mathbf{n}(\%)$ & $9(9)$ \\
\hline Male & $59(59)$ \\
\hline Female & $31(31)$ \\
\hline Presenting complaints, $\mathbf{n ( \% )}$ & $20(20)$ \\
\hline Claudication & $16(16)$ \\
\hline Rest pain & \\
\hline Gangrene/ ulceration & $86(86)$ \\
\hline Erectile dysfunction & $37(37)$ \\
\hline Co-morbidity, $\mathbf{n}(\%)$ & $33(33)$ \\
\hline Smoking & $27(27)$ \\
\hline Diabetes mellitus & $26(26)$ \\
\hline Dyslipidaemia & $9(9)$ \\
\hline Coronary artery disease & \\
\hline Hypertension & $44(44)$ \\
\hline Chronic kidney disease & $31(31)$ \\
\hline Disease severity (TASC II class) , $\mathbf{n}(\%)$ & $15(15)$ \\
\hline A & $10(10)$ \\
\hline B & $95(95)$ \\
\hline C & $2(2)$ \\
\hline D & $3(3)$ \\
\hline Endovascular treatment, $\mathbf{n}(\%)$ & \\
\hline Stent & \\
\hline Catheter-Directed Thrombolysis & \\
\hline Stent + Catheter-Directed Thrombolysis & \\
\hline Data are presented as mean (SD) and $n(\%)$ & \\
\hline TASC II- Transatlantic intersociety consensus & \\
\hline & \\
\hline
\end{tabular}

\section{Patients as per post procedure complications.}

m Contrast Induced Nephropathy m Hematoma None

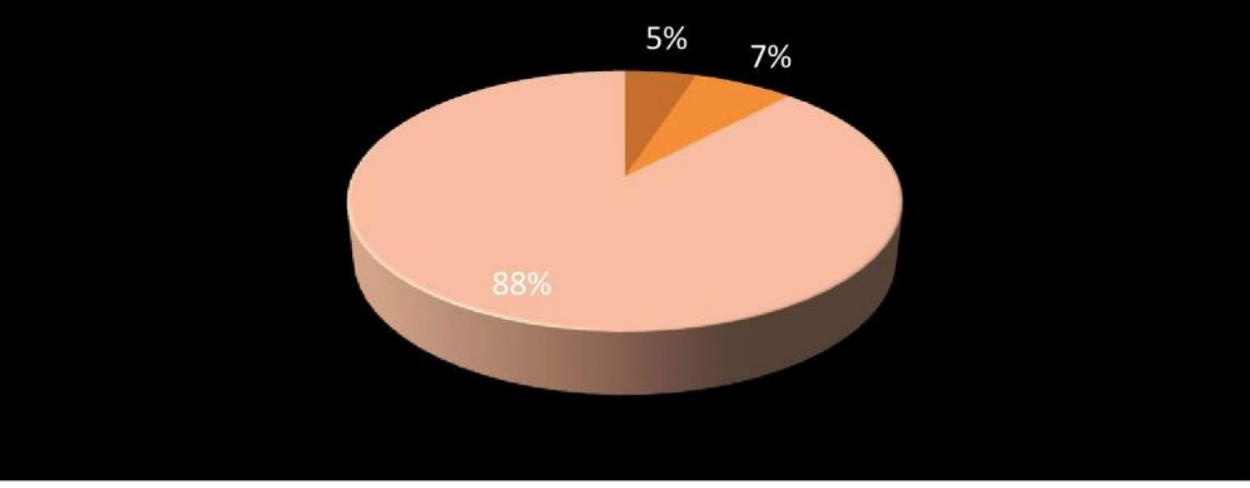

Figure 1. Procedural complications 


\begin{tabular}{|l|c|}
\hline \multicolumn{2}{|l|}{ Table 2. Stents patency rate at $\mathbf{3}$ and $\mathbf{6}$ months (N=98) } \\
\hline Duration & Stent patency, $\mathbf{n}(\%)$ \\
\hline 3 months & $97(98.9)$ \\
\hline 6 months & $95(96.9)$ \\
\hline
\end{tabular}

All the patients had symptomatic improvement post procedure. At 3 months and 6 month follow up symptomatic improvement persisted in $99 \%$ and $97 \%$ patients respectively. Improved ulcer healing was seen in majority of patients with non-healing ulcers (Fig.2).

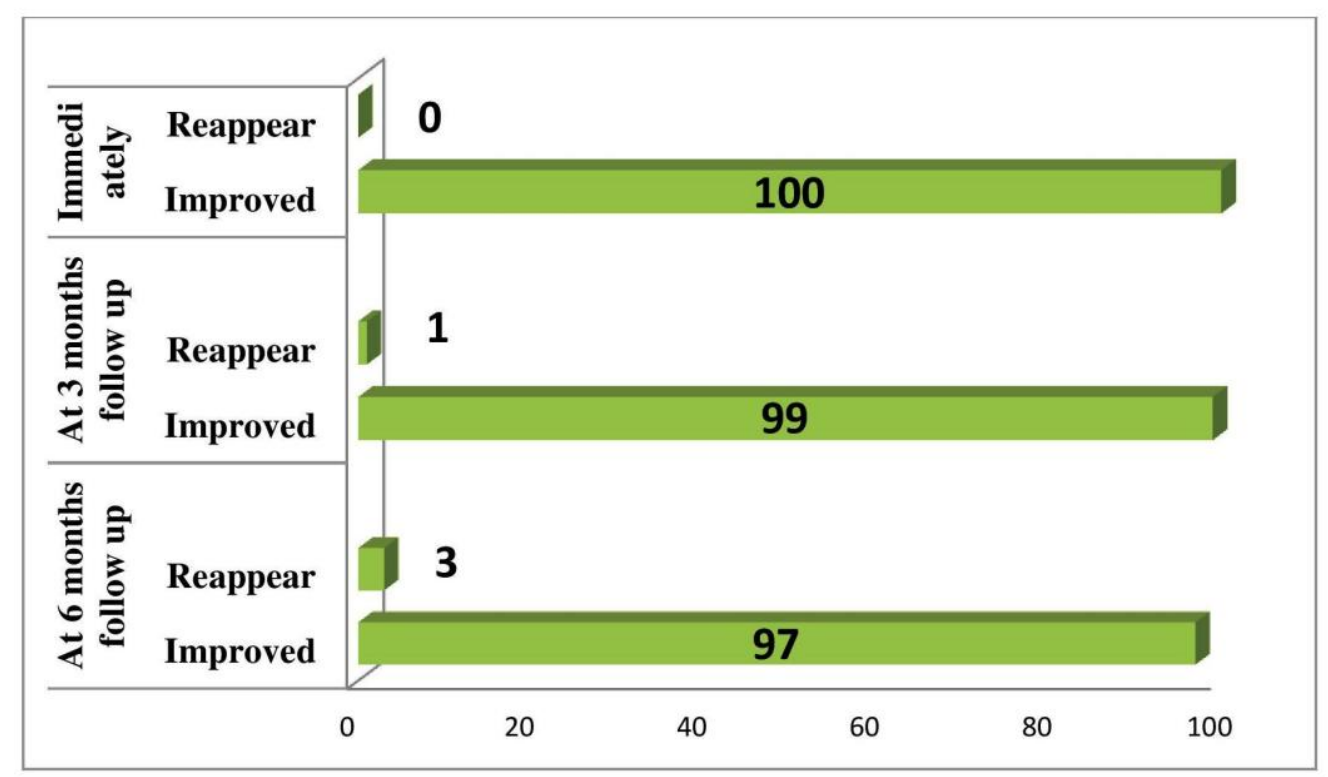

Figure 2. Symptom status immediately post procedure, at 3 and 6 months

\section{Discussion}

Endovascular therapy is a less invasive method, associated with fewer complications and shorter hospital stay. According to the TASC II guidelines, for patients with type $C$ and $D$ lesions, the recommended treatment is surgery (9). However, due to increased age and other comorbidities in such patients; surgery is frequently contraindicated $(10,11)$.

In our study $5 \%$ of study participants developed contrast induced nephropathy. A similar study by Kim $\mathrm{TH}$ et al. (12) reported contrast induced nephropathy in three patients (6.1\%) after the procedure. In studies conducted by liu et al. (13) and Rebellino et al. (14), very few patients suffered from contrast induced nephropathy while in present study nephropathy was possibly due to old age of patients and comorbid conditions.

Access site hematoma was almost same in all these studies which were nearly $5 \%$.
In our study, we reported a $96.93 \%$ primary patency rate. $97 \%$ patients in our study reported symptomatic improvement at 6 months. In the study done by Bjorses et al. (15) symptomatic improvement was found to be below 90\%. De Roeck et al. (16) and Gandini et al. (17) reported symptomatic improvement in almost all the patients. In the studies by De Roeck et al. (16) and Kashyap et al. (18), primary patency rate was less than $95 \%$. Whereas Bjorses et al. (15) and Gandini et al. (17) reported primary patency rate of more than $95 \%$.

Various studies on endovascular treatment for aortoiliac lesions have reported different patency rate at follow-up according to the lesion type. Studies by Wiesinger et al. (19) and Sabri et al. (20) had primary patency rate of $90.7 \%$ at 1 year and $92 \%$ at 2-year respectively in TASC II D lesion type. While Humphries et al. (21) showed primary patency rate of $72 \%$ at 3year for TASC II D lesion type. 
Studies by Bosies et al. (22) and Aihara et al. (23) with lesion type TASC II C and D have reported the patency rate of $91.1 \%$ and $87 \%$ at one year respectively while present study with lesion type C \& D had 95\% patency rate at 6-month follow-up.

Patients suffering from AIOD are usually older with other risk factors and concomitant cardiac disease. Open surgery for such patients carries risk of high morbidity and mortality. Endovascular therapy should be considered as initial treatment modality in older patients with other comorbidities in view of lower post procedure complication rate, good long-term results and lower hospital stay. Moreover, the cost of treatment is also lower with endovascular therapy (24). Open surgical treatment should be considered for patients who develop recurrent occlusion.

\section{Limitations of the study}

Our study has several limitations. First, the sample size was small, which may have led to selection bias. Second, the follow-up period was relatively short compared to other similar studies. And finally, our study lacked a comparator arm.

\section{Conclusion}

Endovascular therapy in aorto-iliac occlusive disease is a safe, effective and low cost treatment option with high patency rate and symptomatic improvement in short-term. Larger and long-term prospective studies may provide definitive answers regarding potential advantages of endovascular treatment over surgery for aorto-iliac disease. Nevertheless, with continuing developments in endovascular techniques and devices as well as growing experience of interventionist, indications for endovascular treatment of aorto-iliac occlusive disease will be broadened.

Peer-review: External and internal Conflict of interest: None to declare Authorship: D.J., T. M., R.C., P.R., K.P., A.B., R.P., A. D. are equally contributed to preparation of manuscript and fulfilled authorship criteria

Acknowledgement and funding: This work was supported by U. N. Mehta Institute of Cardiology and Research Centre itself and received no specific grant from any funding agency, commercial or not for profit sectors

\section{References}

1.Olin JW, Sealove BA. Peripheral artery disease: current insight into the disease and its diagnosis and management. Mayo Clin Proc 2010; 85: 678-92.
2.Aggarwal V, Waldo SW, Armstrong EJ. Endovascular revascularization for aorto-iliac atherosclerotic disease. Vasc Health Risk Manag 2016; 12: 117.

3.Thukkani AK, Kinlay S. Endovascular intervention for peripheral artery disease. Circ Res 2015; 116: 1599613.

4.Robertson L, Paraskevas KI, Stewart M. Angioplasty and stenting for peripheral arterial disease of the lower limbs: an overview of Cochrane Reviews. Cochrane Database Syst Rev 2017; 2017: CD012542

5.Varaki ES, Gargiulo GD, Penkala S, Breen PP. Peripheral vascular disease assessment in the lower limb: a review of current and emerging non-invasive diagnostic methods. Biomed Eng Online 2018; 17: 127.

6.Dellehunt RE, Manna B. Aortofemoral bypass. In: StatPearls. StatPearls Publishing, Treasure Island (FL); 2019. Available from https://www.ncbi.nlm.nih.gov/books/NBK542328 PMID: 31194468

7.Moeini M, Tadayon Najafabadi B, Zafarghandi M, Salimi J, Taghavi M, et al. Endovascular treatment showing promising short-term results in patients with total bilateral aorto-iliac occlusion. Iran J Radiol 2018; 15: e61843.

8.Jia X, Sun ZD, Patel JV, Flood K, Stocken DD, Scott DJ. Systematic review of endovascular intervention and surgery for common femoral artery atherosclerotic disease. Br J Surg 2019; 106: 13-22.

9.Norgren L, Hiatt WR, Dormandy JA, Nehler MR, Harris KA, Fowkes FG. Inter-society consensus for the management of peripheral arterial disease (TASC II). J Vasc Surg 2007; 45: S5-67.

10.Brewster DC. Clinical and anatomical considerations for surgery in aortoiliac disease and results of surgical treatment. Circulation 1991; 83(2 Suppl): 142-52.

11.Murabito JM, D'Agostino RB, Silbershatz H Wilson WF. Intermittent claudication. A risk profile from The Framingham Heart Study. Circulation 1997; 96: 44-49. 12.Kim SM, Cha RH, Lee JP, Kim DK, Oh KH, Joo KW, et al. Incidence and outcomes of contrast-induced nephropathy after computed tomography in patients with CKD: a quality improvement report. Am J Kidney Dis 2010; 55: 1018-25.

13.Liu M, Zhang F. Endovascular management of aorta-iliac stenosis and occlusive disease by kissingstent technique. Stem Cells Int 2016; 2016. 
14.Rabellino M, Chas J, Lucas L, Cesáreo V, Kotowicz V, García-Monaco R. Endovascular treatment in aortoiliac occlusive disease. Argent J Cardiol 2016; 84: 243-6.

15.Björses K, Ivancev K, Riva L, Manjer J, Uher P, Resch T. Kissing stents in the aortic bifurcation-a valid reconstruction for aorto-iliac occlusive disease. Eur J Vasc Endovasc Surg 2008; 36: 424-31.

16.De Roeck A, Hendriks JM, Delrue $F$, Lauwers $P$, Van Schil $P$, De Maeseneer $M$, et al. Long-term results of primary stenting for long and complex iliac artery occlusions. Acta Chirurgica Belgica 2006; 106: 187-92.

17. Gandini R, Fabiano S, Chiocchi M, Chiappa R, Simonetti G. Percutaneous treatment in iliac artery occlusion: long-term results. Cardiovasc Intervent Radiol 2008; 31: 1069-76.

18.Kashyap VS, Pavkov ML, Bena JF, Sarac TP, O'Hara PJ, Lyden SP, et al. The management of severe aortoiliac occlusive disease: endovascular therapy rivals open reconstruction. J Vasc Surg 2008; 48: 14517.

19.Wiesinger B, Beregi JP, Oliva VL, Dietrich T, Tepe G, Bosiers $M$, et al. PTFE-covered self-expanding nitinol stents for the treatment of severe iliac and femoral artery stenoses and occlusions: final results from a prospective study. J Endovasc Ther 2005; 12: 240-6.
20.Sabri SS, Choudhri A, Orgera G, Arslan B, Turba UC, Harthun NL, et al. Outcomes of covered kissing stent placement compared with bare metal stent placement in the treatment of atherosclerotic occlusive disease at the aortic bifurcation. J Vasc Interv Radiol 2010; 21: 995-1003.

21. Humphries MD, Armstrong E, Laird J, Paz J, Pevec W. Outcomes of covered versus bare-metal balloonexpandable stents for aortoiliac occlusive disease. J Vasc Surg 2014; 60: 337-44.

22.Zeller T, Baumgartner I, Scheinert D, Brodmann M, Bosiers M, Micari A, et al. Drug-eluting balloon versus standard balloon angioplasty for infrapopliteal arterial revascularization in critical limb ischemia: 12-month results from the IN.PACT DEEP randomized trial. J Am Coll Cardiol 2014; 64: 1568-76.

23.Aihara H, Soga Y, lida O, Suzuki K, Tazaki J, Shintani $\mathrm{Y}$, et al. Long-term outcomes of endovascular therapy for aortoiliac bifurcation lesions in the real-Al registry. J Endovasc Ther 2014; 21: 25-33.

24.Indes JE, Mandawat A, Tuggle CT, Muhs B, Sosa JA. Endovascular procedures for aorto-iliac occlusive disease are associated with superior short-term clinical and economic outcomes compared with open surgery in the inpatient population. J Vasc Surg 2010; 52: $1173-9$.

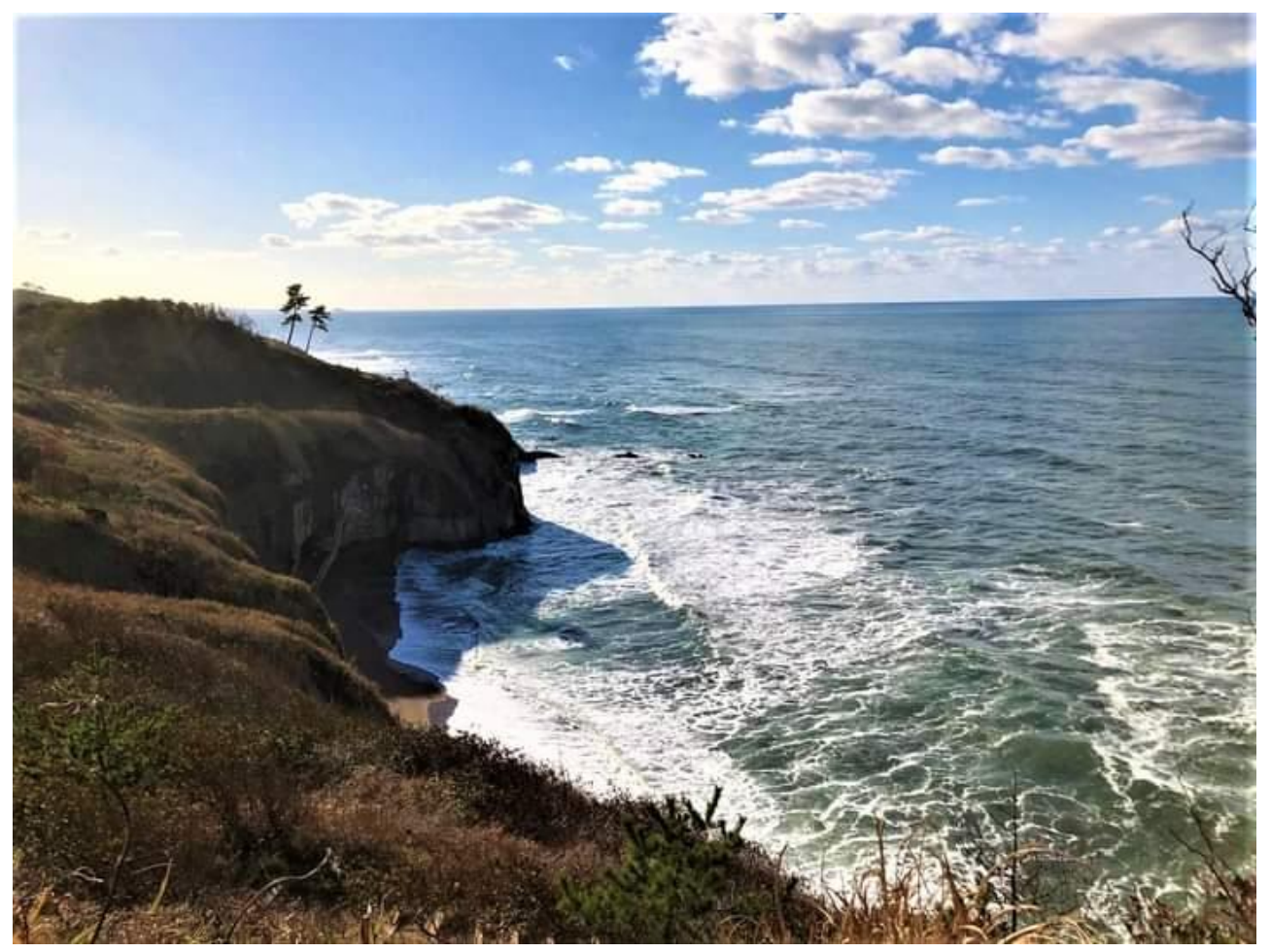

Pacific ocean coast, Japan 2021. Isao Arikawa, Japan. 